\title{
Experimental evidence of fatty acid limited growth and survival in Pacific cod larvae
}

\author{
L. A. Copeman ${ }^{1,2, *}$, B. J. Laurel ${ }^{1}$ \\ ${ }^{1}$ Fisheries Behavioral Ecology Program, Alaska Fisheries Science Center, National Marine Fisheries Service, NOAA \\ ${ }^{2}$ Cooperative Institute for Marine Resources Studies, Oregon State University, Hatfield Marine Science Center, \\ Newport, Oregon 97365, USA
}

\begin{abstract}
Changing environmental conditions in the North Pacific are altering the lipid/fatty acid (FA) composition of zooplankton assemblages, but the consequences to resident fish larvae are unknown. In the laboratory, we reared Pacific cod Gadus macrocephalus larvae over 4 wk on prey enriched with varying levels of 2 essential FAs (docosahexaenoic acid, DHA, 22:6 $\omega$-3, and eicosapentanoic acid, EPA, 20:5 $\omega$-3) to determine how this species responded to such changes in prey quality. Ratios of DHA:EPA were chosen to represent the natural variation observed in zooplankton of the North Pacific. We tested the hypotheses whether (1) energetically similar diets comprised of varying levels of DHA and EPA affect growth and survival in Pacific cod larvae, and (2) the highest levels of DHA:EPA (2:1) are optimal for Pacific cod larvae, as it has been shown for Atlantic species. Pacific cod larvae grew fastest with diets containing high levels of $\omega-3$ polyunsaturated fatty acids (PUFA > $22 \%)$. Diets with the same total lipid content but different DHA:EPA ratios $(<0.1: 1$ to $2: 1)$ also mediated growth and lipid composition of the larvae. Unlike Atlantic cod, Pacific cod larvae did not show as high a requirement for DHA relative to EPA but rather achieved largest size-at-age with intermediate DHA:EPA ratios (0.8:1 to 1.1:1). This range most closely resembled DHA:EPA ratios reported from North Pacific copepods, suggesting anomalous years with an over- or under-abundance of DHA-rich dinoflagellates or EPA-rich diatoms may be detrimental to survival and growth of Pacific cod larvae in the field.
\end{abstract}

KEY WORDS: Gadus macrocephalus $\cdot$ Essential fatty acids $\cdot$ DHA $\cdot$ EPA $\cdot$ Prey quality

\section{INTRODUCTION}

Prey quality is an important but poorly understood factor regulating growth and survival in larval fish (Cushing 1990, Munk 1997, Beaugrand et al. 2003). Changing climate and emerging ocean acidification have the potential to affect fish communities through large-scale changes in planktonic communities. Changes in dietary quality for larval fish can be manifested both through changes in available zooplankton populations or through compositional change in specific nutritional components (i.e. essential fatty acids) within a given zooplankton prey species such as copepods. In the North Pacific, zooplankton species composition changes dramatically between warm and cold years (Batten \& Welch 2004), with cold-years typified by large boreal copepods and warm years characterized by higher numbers of small, southern species (Mackas et al. 2007). Further, biochemical changes in a major North Pacific copepod species, Neocalanus plumchrus, have been correlated with changes in phytoplankton species abundance and have resulted in shifts in zooplankton fatty acid (FA) composition (ElSabaawi et al. 2009a). However, while qualitative changes in the planktonic community such as these are hypothesized to impact growth and survival of marine fish larvae, they have rarely been examined explicitly. This is largely due to the difficulty in determining a priori which qualitative components of prey are limiting (e.g. prey size, energy, proximate composition, etc.) and the difficulty in manipulating those conditions experimentally for marine fish larvae (Rainuzzo et al. 1997). 
From aquaculture studies, lipids and FAs are considered to be a limiting factor in determining prey quality for cold-water marine fish, as they play a vital role both as a source of energy and as important structural components of cell membranes (Sargent et al. 1989, Arts et al. 2001). In particular, polyunsaturated fatty acids (PUFAs) have been shown to be a critical component of larval fish nutrition as they affect growth, survival, metamorphosis and pigmentation in many species (Wantanabe 1993, Sargent et al. 1999, Copeman et al. 2002).

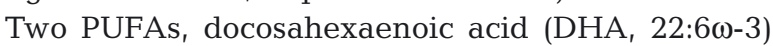
and eicosapentaenoic acid (EPA, 20:5 dant in organisms found in cold-water marine ecosystems, but are considered essential fatty acids (EFAs) to marine fish as they cannot be synthesized in adequate amounts from short chain precursors. Marine larval fish must therefore rely on dietary input of DHA and EPA stemming from primary production (Sargent 1995, Arts et al. 2001, Budge et al. 2001, Copeman \& Parrish 2003). Levels of EPA in plankton have been correlated with diatom production whereas DHA is found at higher proportions in dinoflagellates (Dunstan et al. 1994, Parrish et al. 2000, Stevens et al. 2004). Although both FAs have been found to be essential to marine fish larvae, many species have shown membrane specificity to be higher for DHA than EPA (Rodriguez et al. 1997, Copeman et al. 2002). Given that DHA is naturally found at high levels in neural tissue, it is thought to play a specialized role in neural cell membrane structure and function (Bell \& Dick 1991). Therefore, higher dietary EPA in comparison to DHA is postulated to have a negative effect on larval neural function and, consequently, on growth and survival (Bell et al. 1995, Rodriguez et al. 1997).

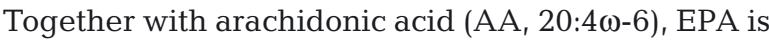
also an important substrate for the formation of biologically active localized hormones such as prostaglandins (Sargent et al. 1999). Localized hormones have been indicated to be important in a wide range of fish physiological processes such as stress responses, ionic regulation and pigmentation development (Sargent 1995). EPA and AA are both substrates for the formation of eicosanoids, with AA being the preferred one and producing eicosanoids of high biological activity (Bell et al. 1994). EPA produces eicosanoids of lower biological activity and hence modulates the efficiency of AA. Therefore, it is often important to consider the ratio of DHA:EPA:AA as has been indicated in recent nutritional larval fish studies on Atlantic species (Copeman et al. 2002, Garcia et al. 2008a).

Generally, a DHA:EPA ratio of 2:1 in larval fish diets is cited as being optimal for growth and survival (Sargent 1995), largely based on egg composition of Atlantic species. However, Saito \& Kotani (2000) found FA profiles of wax esters from 4 North Pacific copepod species that had low DHA:EPA ratios $(0.2: 1$ to $0.4: 1)$. Recently, El-Sabaawi et al. (2009a) showed that DHA:EPA ratios from the North Pacific were lower than those from the Atlantic, but varied considerably depending on the relative abundance of EPA-rich diatoms and DHA-rich dinoflagellates (0.3:1 to 1.1:1). Interestingly, Laurel et al. (2010) found that DHA:EPA ratios in Pacific cod eggs were 1.4:1, i.e. lower than the 2:1 reported from their Atlantic congeners. The degree to which low DHA:EPA ratios affect Pacific marine fish larvae remains uncertain, largely because the majority of cold-water larval fish nutrition is based on Atlantic aquaculture species (Sargent et al. 1999) with little comparison to wild zooplankton assemblages (St. John et al. 2001).

Here we designed a laboratory experiment to examine how changes in DHA and EPA affected the growth and survival in the larvae of a Pacific cold-water fish, Pacific cod Gadus macrocephalus. This species was chosen because it (1) is highly abundant and plays an important role in predator-prey dynamics in the North Pacific (Hunt et al. 2002) and (2) makes an interesting comparison with its well-studied Atlantic congener, Gadus morhua. We tested the hypotheses whether (1) energetically similar diets comprising varying levels of EPA and DHA influence size-at-age and survival in Pacific cod larvae, and (2) high levels of DHA:EPA (e.g. 2:1) are optimal for marine fish larvae in the Pacific as it has been shown for Atlantic species. We discuss our results in relation to natural variation in the lipid and FA composition of larval prey in the North Pacific.

\section{MATERIALS AND METHODS}

Experimental design. Four rotifer enrichments were formulated with varying levels of the essential fatty acids DHA and EPA, and thus variable DHA:EPA ratios (Dr. Moti Harel, Advanced BioNutrition). Enriched rotifers were harvest twice daily throughout the experiment and fed to cod larvae for $4 \mathrm{wk}$. During this time we measured changes in lipid composition of the larvae while simultaneously monitoring size-atage and survival.

Rotifer emulsions. Of the 4 experimental emulsions, Diet 1 was high in monounsaturated fatty acids (MUFAs) and served as a control, while the experimental Diets 2, 3 \& 4 were high in PUFAs (Table 1). The target ratios of DHA:EPA in rotifers ranged from $<0.1: 1$ (Diet 1) to 2:1 (Diet 4). The 3 PUFA emulsions were formulated by blending different ratios of algae oil (DHAsco-S ${ }^{\mathrm{TM}}$ ) and cod liver oil. The DHA-rich algal oil was extracted from the heterotrophically grown Schizochitrium sp. (Martek BioSci, Harel et al. 2002). 
The FA composition of DHAsco-S was $27 \%$ DHA and no EPA while cod liver oil contained $\sim 20 \%$ DHA and $30 \%$ EPA (information provided by manufacturer). The control emulsion was prepared using only olive oil, which was low in PUFA. A mixture of $5 \%$ lecithin, $1 \%$ vitamin $\mathrm{E}, 1 \%$ ascorbic acid and 1\% Tween-80 (w:oil weight) was added to the oils. Oil mixtures were emulsified with equal amounts of distilled water by (1) homogenizing at low speed (Ultra-turrax T8, IKA Labortechnik) for $15 \mathrm{~s}$ and (2) sonicating for an additional $15 \mathrm{~s}$ at one third of the maximum sonication energy level (Sonifier 450, Branson Sonic Power). Emulsions were stored under nitrogen at $4^{\circ} \mathrm{C}$ for daily use.

Rotifer culture and enrichment. Rotifers were reared in a continous high-density rotifer culture system (150 l) and maintained on Nannochloropsis Premium 3600 (Suantika et al. 2000) obtained from Aquatic Ecosystems, Inc). At 08:00 $\mathrm{h}$ and 16:00 $\mathrm{h}$ daily, rotifers were harvested and placed in smaller enrichment vessels in order to produce 2 batches of enriched rotifers for daily larval fish feedings. Rotifer enrichments were carried out at a density of 500000 ind. $1^{-1}$ under gentle aeration with an air stone placed in the bottom of the conical 501 vessel. Rotifer batches were enriched for 8 or $16 \mathrm{~h}$ (08:00 to $16: 00$ or $16: 00$ to $08.00 \mathrm{~h}$ ) each $24 \mathrm{~h}$ period by adding $0.1 \mathrm{~g}$ of oil per liter of rotifier culture at the beginning of each enrichment (Dhert et al. 2001, Copeman et al. 2002). Emulsion oils were blended for $\sim 30 \mathrm{~s}$ in $2 \mathrm{l}$ of distilled water and added to enrichment vessels. Enriched rotifers were sampled from each ves-

Table 1. Ingredients of the 4 different oil emulsions, and lipid class composition of the 4 rotifer diets enriched for 8 or $16 \mathrm{~h}$ using these oil emulsions (mean \pm $\mathrm{SEM}, \mathrm{n}=4$ ). In addition, all emulsions contained $5 \%$ lecithin, $1 \%$ vitamin $\mathrm{E}, 1 \%$ ascorbic acid and $1 \%$ Tween-80 (w/oil weight). Enriched rotifer diets contained $<2.5 \%$ hydrocarbons, ethyl \& metyl esters, ethyl \& methyl ketones, alcohols, and diacylglycerols (not specified in the table)

\begin{tabular}{|c|c|c|c|c|}
\hline & Diet 1 & Diet 2 & Diet 3 & Diet 4 \\
\hline \multicolumn{5}{|c|}{ Ingredients of oil emulsions (g) } \\
\hline DHAsco-S & 0 & 3.5 & 9.5 & 21.8 \\
\hline Cod liver oil & 0 & 37.7 & 25.5 & 25.5 \\
\hline Olive oil & 45 & 3.8 & 10 & 10 \\
\hline Water & 50 & 50 & 50 & 50 \\
\hline Total $\omega-3$ & 0 & 8.7 & 8.7 & 8.7 \\
\hline \multicolumn{5}{|c|}{ Lipids of enriched rotifers } \\
\hline Total lipids ( $\left.\mu g \mathrm{mg}^{-1}\right)$ & $132.8 \pm 42.8$ & $133.7 \pm 65.1$ & $80.1 \pm 38.9$ & $107.2 \pm 7.3$ \\
\hline \multicolumn{5}{|c|}{ Lipid classes (\% total lipid) } \\
\hline Steryl/wax esters & $2.6 \pm 0.2$ & $1.8 \pm 0.4$ & $1.6 \pm 1.0$ & $2.2 \pm 0.6$ \\
\hline Triacylglycerols & $35.0 \pm 4.3$ & $44.2 \pm 3.5$ & $35.4 \pm 5.8$ & $38.0 \pm 3.8$ \\
\hline Free fatty acids & $7.7 \pm 1.1$ & $6.0 \pm 1.5$ & $6.7 \pm 1.2$ & $7.4 \pm 0.9$ \\
\hline Alcohols & $2.7 \pm 1.3$ & $5.6 \pm 0.5$ & $6.7 \pm 2.5$ & $3.7 \pm 2.7$ \\
\hline Sterols & $3.7 \pm 0.5$ & $3.3 \pm 0.5$ & $8.8 \pm 4.9$ & $6.2 \pm 1.0$ \\
\hline $\begin{array}{l}\text { Acetone mobile polar } \\
\text { lipids }\end{array}$ & $6.1 \pm 0.7$ & $8.7 \pm 1.3$ & $16.2 \pm 6.5$ & $11.0 \pm 2.1$ \\
\hline Phospholipids & $38.5 \pm 6.0$ & $27.7 \pm 0.8$ & $22.0 \pm 7.5$ & $29.4 \pm 2.6$ \\
\hline
\end{tabular}

sel in triplicate for lipid analysis 2 times each for the 8 and $16 \mathrm{~h}$ experiment.

Larviculture. Fish larvae for feeding experiments were reared in the laboratory from eggs collected from spawning adults. In April 2008, 2 female and 3 male Pacific cod were caught by commercial jigging gear from spawning grounds in Chiniak Bay, Kodiak Island, Alaska. The gametes were mixed and placed into $4 \mathrm{l}$ incubation trays at $4^{\circ} \mathrm{C}$. At $24 \mathrm{~h}$ post-fertilization, fertilized eggs were shipped in insulated containers filled with $4^{\circ} \mathrm{C}$ chilled seawater to Alaska Fisheries Science Center (AFSC) laboratory facilities in Newport, Oregon. Eggs were transferred to 41 plastic flow-through trays and incubated at $4^{\circ} \mathrm{C}$ until hatching, as described by Laurel et al. (2008). Hatching occurred 19 to $22 \mathrm{~d}$ post-fertilization. Hatched larvae were transferred into 1001 cylindrical upwelling tanks, which were stocked with larvae from multiple hatching trays in order to avoid differential effects due to egg-incubation environment. To each of the 4 dietary treatments, 3 larval tanks were assigned for a total of 12 larval first-feeding culture tanks.

The feeding experiment was carried out in 12 conical upwelling 1001 fiberglass tanks with dark green interiors. Larvae were randomly sorted into 3 replicate tanks assigned to each of 4 dietary treatments. Tanks were kept at 12:12 $\mathrm{h}$ photoperiod to approximate day length conditions experienced by cod larvae in the Gulf of Alaska in March-April. Overhead fluorescent bulbs provided a photon level of $6.7 \mu \mathrm{mol} \mathrm{m} \mathrm{m}^{-2} \mathrm{~s}^{-1}$ at the water surface. Water was supplied at a

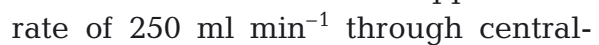
bottom intake to minimize disturbance to the larvae. Gentle aeration by an airstone provided additional circulation in the tanks. From Day 2 until the end of the experiment, differentially enriched rotifers were added to tanks twice per day at a density of 4000 ind. $\mathrm{l}^{-1}$ as considered optimal, saturating food conditions for cod larvae (Brown et al. 2003). Tanks were 'greened' by adding Nannochloropsis Premium 3600 (Aquatic Ecosystems, Inc) twice daily at a density of $1.06 \times 10^{9}$ cells $\mathrm{l}^{-1}$. Greening larval tanks with microalgae provides larviculture benefits that are not fully understood, but are related to beneficial effects on foraging activity and increased nutritional condition in larvae through direct ingestion of microalgae (van der Meeren et al. 2007).

Size-at-age and survival. Fish larvae were sacrificed from experimental tanks at Weeks 1, 2, 3 \& 4 for morpho- 
metric measurements. From each of the 3 replicate tanks per treatment, 10 larvae tank ${ }^{-1} \mathrm{wk}^{-1}$ were taken, i.e. 30 larvae treatment $^{-1}$, for measuring standard length (length in $\mathrm{mm}$ from the tip of the snout to the end of the notochord, SL), and body depth (width in $\mathrm{mm}$ of the larvae just posterior to the anus not including the fin fold, BD), using an image analysis system connected to a dissecting microscope. For dry weight (DW) determination, the 10 larvae were rinsed collectively in $3 \%$ ammonium formate solution to rid excess salt and inorganic material, placed on $1.5 \mathrm{~cm}^{2}$ preweighed aluminum foils and dried in an oven at $68^{\circ} \mathrm{C}$ for $48 \mathrm{~h}$. DW of pooled larvae was determined with a microbalance (Sartorius R16OP) to the nearest $\mu g$ resulting in 1 measure tank $^{-1}$ and 3 measures treatment ${ }^{-1}$ $\mathrm{wk}^{-1}$. Average individual DW was calculated by subtracting the foil weight and dividing by the number of individuals on the foil. Foils were then stored in a desiccator and reweighed within $1 \mathrm{~h}$. Survival was determined at the end of the study by counting all remaining larvae left in experimental tanks.

Lipid analysis. Total lipids and lipid classes were measured in both rotifers and larval fish to determine differences in dietary quality and their effects on larval condition. The major lipid classes in fish are triacylglycerols (TAG), sterols (ST) and phospholipids (PL). TAG is generally considered as the major storage lipid class in larval fish while PL and ST are important components of cellular membranes. However, recent studies have shown that PL is also important as an energy source in eggs and larval fish as well as in low-lipid juveniles (Evans et al. 1998, Copeman et al. 2008, Laurel et al. 2010). Relative improvements in larval condition in other species, such as herring or Atlantic cod have been attributed to elevated total lipid, TAG per DW and TAG:ST ratios (Fraser 1989, Lochman et al. 1995).

Lipid samples of larvae were collected at the beginning of the experiment (time zero) and at the end of Week 2 and 4. Not enough larvae survived Diet 1 to sample at Week 4 so only larvae from the 3 high PUFA diets were sampled for lipids at this end point. Fifty larvae per tank, and 3 samples per diet, were collected at Weeks 2 \& 4. Individuals were pooled in order to obtain sufficient material for lipid class and FA analysis. Lipids were extracted in chloroform:methanol according to Parrish (1987) using a modified Folch procedure (Folch et al. 1957). Lipid classes were determined by thin layer chromatography with flame ionisation detection (TLC-FID) using a MARK V Iatroscan (Iatron Laboratories) as described by Parrish (1987). Extracts were spotted on silica gel coated Chromarods and lipid classes were separated in a 3 stage system. The separation was developed in (1) hexane:diethyl ether:formic acid (98.95:1.00:0.05) for $20 \mathrm{~min}$, (2), hexane:diethyl ether:formic acid (79:20:1) for $40 \mathrm{~min}$,
(3), 100\% acetone (15 min) followed by 10 min chloroform:methanol:water (5:4:1). After each separation, the rods were scanned and the 3 chromatograms were combined using T-data scan software (RSS, Bemis, Tennessee, USA). The signal detected (mV) was quantified using lipid standards (Sigma, St. Louis, Missouri, USA). Lipid classes were expressed both in relative ( $\mathrm{mg} \mathrm{g}^{-1}$ wet weight) and absolute amounts ( $\mu \mathrm{g}$ ind ${ }^{-1}$ ).

Total lipid was analysed for FA composition. Fatty acid methyl esters (FAME) were prepared by transesterification with $14 \% \mathrm{BF}_{3}$ in methanol at $85^{\circ} \mathrm{C}$ for 90 min (Morrison \& Smith 1964, Budge 1999). The FAMEs were analyzed on a HP 6890 GC FID equipped with a 7683 autosampler and a ZB wax GC column (30 cm long, internal diameter $0.25 \mu \mathrm{m}$; Phenomenex, USA). The column temperature began at $65^{\circ} \mathrm{C}$ for $0.5 \mathrm{~min}$, ramped to $195^{\circ} \mathrm{C}$ at a rate of $40^{\circ} \mathrm{C} \mathrm{min}{ }^{-1}$, held for $15 \mathrm{~min}$, then ramped to a final temperature of $220^{\circ} \mathrm{C}$ at a rate of $2^{\circ} \mathrm{C} \mathrm{min}^{-1}$. This final temperature was held for $3.25 \mathrm{~min}$. The carrier gas was hydrogen at a flow rate of $2 \mathrm{ml} \mathrm{min}{ }^{-1}$. The injector temperature started at $150^{\circ} \mathrm{C}$ and ramped to a final temperature of $250^{\circ} \mathrm{C}$ at a rate of $200^{\circ} \mathrm{C} \mathrm{min}{ }^{-1}$. The detector temperature stayed constant at $260^{\circ} \mathrm{C}$. Peaks were identified using retention times from standards (37 component FAME, BAME (bacterial fatty acid methyl ester), PUFA 1, PUFA 3; Supelco). Chromatograms were integrated using the HP ChemStation Chromatograghy Software (Version B00.00).

Data analysis. Differences in size-at-age and lipid profiles were performed on tank means. Differences between treatments in size-at-age measurements were analyzed using a repeated measures ANOVA with the explanatory variables being 'dietary treatment', week ('wk'), and the interaction between 'diet' and ' $w k^{\prime}$ ', (Statistix 7, Hicks 1982). There was a significant interaction between the effect of 'wk' and 'diet' on larval size-at-age and therefore, we examined weekly effects of diet on morphometrics and lipid composition using one-way ANOVAs with Tukey's multiple comparison tests. Data were examined for normality, homogeneity and independence to satisfy the assumption of the ANOVA. Significance for all tests was set at $\alpha=0.05$. FA percentage data were arcsine-square root transformed to meet the assumptions of the model. Differences in the lipid classes and FAs of enriched rotifers were compared across diets using a one-way ANOVA with Tukey's multiple comparison tests.

Principal component analysis (PCA) was used to simplify multivariate FA and lipid class data by transforming correlated variables into a set of uncorrelated principal components (Minitab, version 15; Meglen 1992). This technique was employed using 9 highly discriminatory lipid variables from first-feeding Pacific cod larvae, and larvae analyzed at Weeks 2 \& 4 from all 
4 diets. The first 2 principal components (PC1, PC2) accounted for $78 \%$ of the variance among samples, which allowed a display of the major trends within the data set without significant loss of the total original variation. PCA lipid loading coefficients are defined as the correlation coefficients between the original lipid variables and the PCA axis. PCA scores are defined as the position of the original variables along the new PCA axis (Meglen 1992). Lipid variables were chosen based on biological significance and the degree of variance explained by a given lipid class or FA. A correlation matrix was used and coefficients and scores were grouped by cluster analysis using single linkage.

\section{RESULTS}

\section{Enriched rotifers}

Following lipid enrichment there was no significant difference in the total lipid or the proportion of different lipid classes among the 4 batches of rotifers $\left(F_{3,12}=1.35, \mathrm{p}>0.5\right.$, Table 1$)$. On average, DW of all groups comprised $11.3 \%$ lipid, $38 \%$ TAG, and $29 \%$ PL.

Feeding different emulsions to rotifers resulted in 4 diets for cod larvae with significantly different FA profiles (Table 2, p < 0.05). Diets 2, 3 \& 4 (high PUFA) did not vary significantly in their levels of total saturated fatty acids $\left(\sum \mathrm{SFA}=24 \%\right)$, total monounsaturated fatty acids ( $\sum$ MUFA $=33 \%$ ), and total polyunsaturated fatty acids $\left(\sum\right.$ PUFA $\left.=42 \%\right)$. In contrast, control Diet 1 had significantly lower levels of $\sum$ SFA $(22 \%)$, higher ¿MUFA (51\%), and lower $\Sigma$ PUFA (27\%) than the other 3 diets. Elevated levels of $18: 1 \omega-9$ in Diet 1 reflected the utilized olive oil while varying levels of DHA, EPA, AA, and $\omega-6$ DPA were found in the other diets. Diet 2 had a significantly lower DHA:EPA ratio $(0.8: 1)$ than Diet 4 (2:1), while Diet 3 was intermediate (1:1). Levels of total $\omega-3$ differed significantly, ranging from $9 \%$ in Diet 1 to $27 \%$ in Diet 2, while total $\omega-6$ PUFA ranged from $19 \%$ in Diet 4 to $14 \%$ in Diet 2 (Table 2).

\section{Growth and survival}

There was a significant effect of sampling week on the 3 size-at-age parameters (SL, BD \& DW; $F_{3,23}$,
$F>75, \mathrm{p}<0.001)$. Repeated measures also indicated a significant interaction between dietary treatment and the sampling week on all 3 morphometric parameters $\left(F_{9,23}>4.11, \mathrm{p}<0.003\right.$, Fig. 1a). Weekly differences in size-at-age were examined using 1-way ANOVA with Tukey's pairwise comparisons. At Week 4, larvae from Diet 1 were significantly shorter than larvae from the other treatments.

Further, BD of larvae in Diet 1 were significantly different from all other treatments at the end of Week 4 $\left(F_{3,7}=8.3, \mathrm{p}<0.011\right.$, Fig. $\left.1 \mathrm{~b}\right)$.

DW of larvae was also significantly affected by diet as larvae in Diet 1 weighed significantly less than all of the PUFA treatments. Further, larvae in Diets $2 \& 3$ weighed more than larvae from Diet $4\left(F_{3,10}=42.3, \mathrm{p}<\right.$ 0.001, Fig. 1c).

Larvae which were removed for lipid analysis and morphometric measurements were not considered in the calculation of survival. At the end of Week 4, the lowest survival (average $\pm \mathrm{SD}=0.2 \pm 0.2 \%$ ) was found for Diet 1, and not enough larvae were left to collect lipid data. Survival in the high PUFA Diets 2, 3 \& 4 was similar $(6 \pm 3 \%, 6 \pm 3 \%$, and $7 \pm 3 \%$, respectively). 

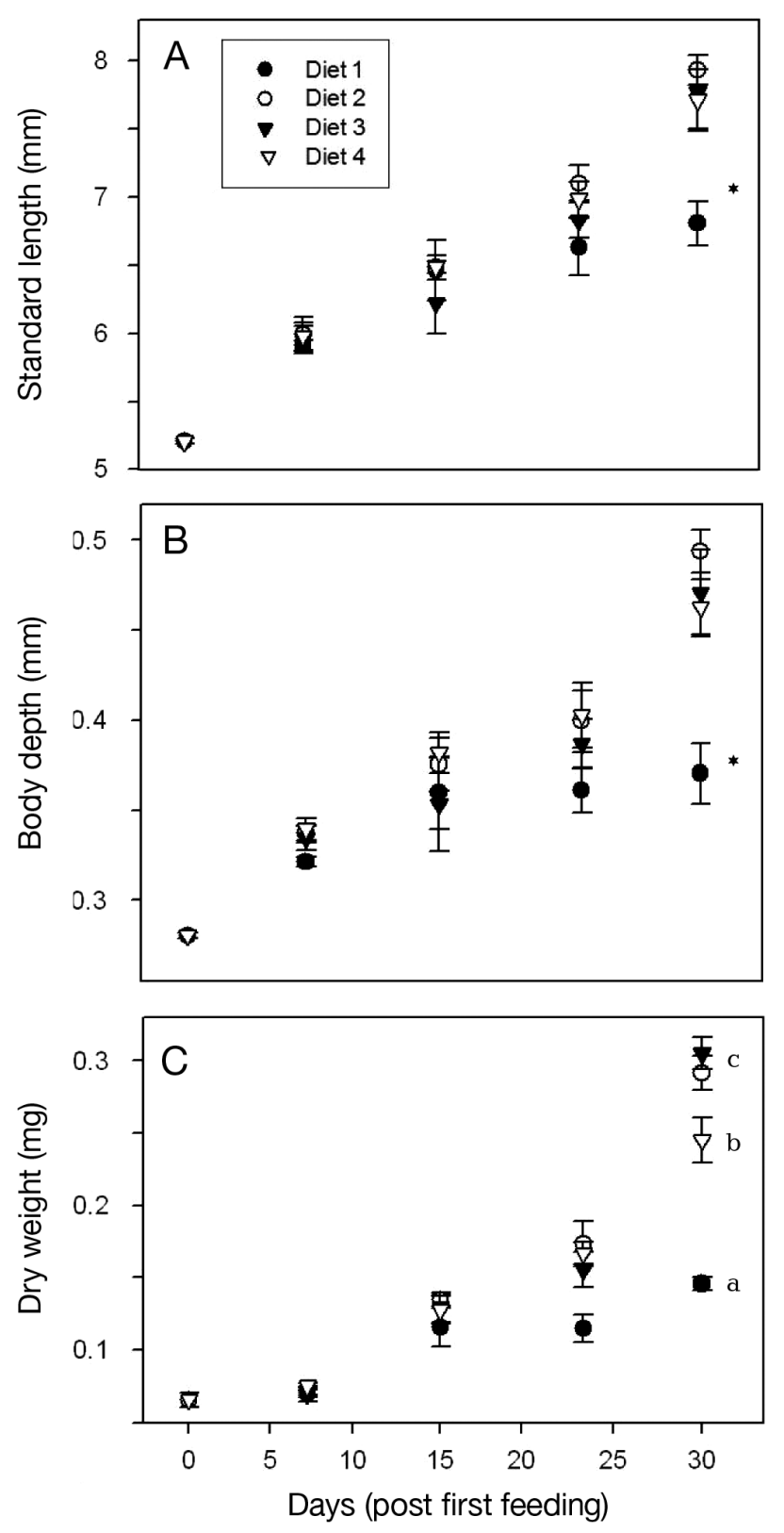

Fig. 1. Gadus macrocephalus. (A) Standard length, (B) body depth and (C) dry weight of Pacific cod larvae reared on 4 differently enriched rotifer diets for the first 4 wk post-hatch. Data are mean \pm SEM. Each symbol represents 30 individuals: $\mathrm{a}, \mathrm{b}, \mathrm{c}$ : different letters represent significant differences among dietary groups (ANOVA, Tukey's multiple comparison). ${ }^{*}$ : Diet

1 was significantly different from all other treatments

\section{Lipid class composition of larvae}

On a DW basis there was no significant increase in total lipid over the course of the entire feeding trial $\left(F_{2,19}=0.07, \mathrm{p}=0.933\right.$, Fig. 2$)$. Larvae had an average of $110 \mu \mathrm{g} \mathrm{mg}^{-1}$ of lipid per DW per individual throughout all treatments during the 3 sampling periods. There was a trend towards higher levels of lipid per DW in Diet 2 compared to the other diets, but this was not significant (Week 2, $F_{2,5}=2.4, \mathrm{p}=0.08$ ). Absolute amount of lipid per larva (average $\pm \mathrm{SD}$ ) did increase from $15.6 \pm 5.1 \mu \mathrm{g}$ in all dietary treatments at Week 2 to $31.9 \pm 10.0 \mu \mathrm{g}$ at the end of the experiment (data not shown).

The effect of dietary treatment on the proportion of TAG present in the larvae was not significant at Week 2 or 4 . However, by pooling all dietary treatments there was a significant effect of sampling week on the proportion of TAG in the larvae $\left(F_{2,19}=22.9, \mathrm{p}<0.001\right)$. Larvae at the beginning of the experiment had significantly higher levels of TAG than larvae at Week 2, while larvae at Week 4 had the highest levels of TAG (Fig. 2b).

The TAG:ST ratio followed the same trend as TAG, with an initial decrease to Week 2 and an increase to Week 4 . However, at Week 4 this ratio showed a significant difference among dietary treatments $\left(F_{2,5}=6.5\right.$, $\mathrm{p}=0.04$ ). At Week 4, larvae in Diet 2 had a significantly higher TAG:ST ratio than larvae in Diet 4 (Fig. 2c). There was no significant effect of diet on the proportion of PL in the larvae at either Week 2 or 4 (Fig. 2d).

\section{Fatty acid composition of larvae}

Total FA per DW varied from $59 \mu \mathrm{g} \mathrm{mg}^{-1}$ in Diet 1 at Week 2 to $87 \mu \mathrm{g} \mathrm{mg}^{-1}$ in Diet 2 at the end of the experiment. When both weeks were pooled, larvae from Diet 2 had significantly more FA per DW than those from Diet $4\left(F_{3,15}=5.23, \mathrm{p}=0.01\right)$.

After just 2 wk of feeding, larvae showed significant differences in the levels of individual FAs (Table 3). For Diet 1, larvae had higher levels of 18:1 $\omega-9$ ( 17\%) and lower levels of many of the longer chain PUFAs than for the other diets. Survival was not assessed at Week 2, however, larvae from Diet 1 showed higher mortality at Week 2 than those in the other PUFA diets. At Week 2, the larval DHA:EPA ratio varied from 1.4:1 in Diet 1 to 4.3:1 in Diet 4 .

After 4 wk of feeding, larvae in the 3 high PUFA diets showed variable levels of individual PUFA but no significant differences ( $p>0.05$ ) in the $\sum$ SFA, $\Sigma$ MUFA or $\sum$ PUFA. DHA levels reached $24 \%$ in Diet 4 , while EPA was highest in Diet $2(12 \%)$. The larval DHA:EPA ratio was significantly higher for Diet 4 (4.2:1) than for either Diet 2 or 3 ( 2:1). Among larvae groups, 22:5 $\omega-6$ varied significantly with the highest levels found in Diet $4(6.5 \%)$ and significantly lower levels in Diets 1 \& 2 (1.7\% \& $3.6 \%$, respectively).

Dietary FA levels affected PUFA retention in larval tissue after only $2 \mathrm{wk}$ of feeding on enriched rotifers (Fig. 3a). Larvae from the control had much higher lev- 

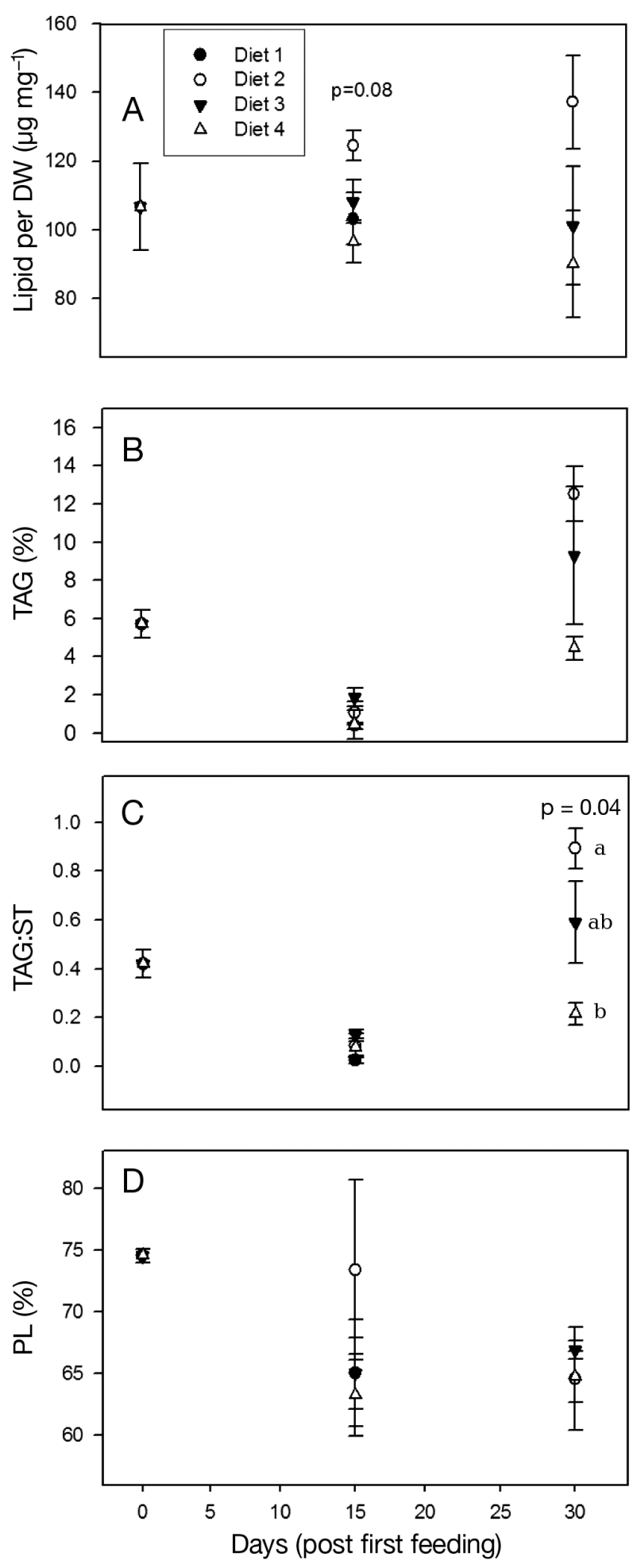

Fig. 2. Gadus macrocephalus. Lipids in Pacific cod reared on 4 differently enriched rotifer diets for the first $4 \mathrm{wk}$ posthatch. (A) Lipid per dry weight (DW), (B) triacylglycerols (TAG) in \%, (C) ratio triacylglycerols:sterols (TAG:ST), (D) phospholipids (PL) in \%. Data are means \pm SEM. ${ }^{\mathrm{a}, \mathrm{b}, \mathrm{C}}$ : different letters represent significant differences among dietary groups (ANOVA, Tukey's multiple comparison) els of all PUFA in their tissues compared to dietary levels $\left(1.7 \times\right.$ more $\sum$ PUFA, $60 \times$ more DHA, Fig. 3a) and higher levels of 18:0, while levels $\sum$ MUFA and 18:1 $\omega-9$ were lower in all larvae than in their diets.

At Week 4, enough larvae to perform lipid analysis remained only in the PUFA enriched Diets 2, $3 \& 4$. Larvae from these diets showed conservation of DHA, $22: 5 \omega-3,22: 5 \omega-6$ ( $\omega 6 \mathrm{DPA}), 20: 4 \omega-6$ (AA), and 18:0 at a rate of 1.5 to $2 \times$ more than in the rotifers. EPA was present at levels approximately equal to that found in the rotifers while MUFA and the short chain PUFA 18:2 $\omega-6$ were present at $\sim 50 \%$ the proportions found in the diet (Fig. 3b).

PCA of 9 FA and lipid class variables simplified the lipid composition of larvae in terms of weekly and dietary effects (Fig. 4). Fig. 4a shows the first 2 principal components and separates larvae in terms of dietary differences. PC1 explained $44 \%$ of the variance, and shows a separation of the PUFA with high levels of DHA and AA on the positive side of the axis and higher levels of total lipids, and EPA on the negative side of the axis. Examination of the lipid loading coefficients for PC 2 (33\%, Fig. 4a) indicated that this axis represented an unsaturation axis, with MUFA loaded on the positive side and high levels of PUFA and increased condition (TAG:ST) on the negative side of the axis.

Examination of sample scores showed that larvae in Diet 4 from Week 2 \& 4 were associated with high levels of DHA, AA, and $\omega 6 \mathrm{DPA}$. These larvae clustered together along the positive side of the axis. On the negative side of the axis, first-feeding larvae clustered together with the 4 -week old larvae from Diet 2, indicating that these larvae had the most similar lipid composition, typified by higher levels of EPA relative to DHA. Larvae from Diet 1 had the lowest condition and low levels of PUFA, with the highest levels of MUFA. They clustered separately at the top of PC2 with an outlying larva from Diet 2. Larvae from Diet 3 showed an intermediate lipid composition.

Fig. 5 shows the relative proportions of EFAs, DHA, EPA and the ratio of DHA:EPA in differently enriched rotifers compared to that reported from wild copepods. We calculated the average and standard error of 6 yr of data on Neocalanus plumchrus from the Straits of Georgia (El-Sabaawi et al. 2009a). DHA, EPA and DHA:EPA ranged from 3.9 to $8.6 \%, 6.6$ to $17 \%$, and 0.3 to $1.1 \%$, respectively (El-Sabaawi et al. 2009a). Proportions of DHA in the rotifers ranged from $0.2 \%$ in Diet 1 to $11.4 \%$ in Diet 4, while EPA was also lowest in Diet $1(5.2 \%)$ and highest in Diet $2(11.1 \%)$. DHA:EPA ratios ranged from $<0.1: 1$ in Diet 1 to $2: 1$ in Diet 4 . A comparison of $N$. plumchrus with our rotifer diets indicated that Diet 2 was the most well-matched diet compared to wild copepods in terms of all 3 PUFA measures (Fig. 5). 
Table 3. Fatty acid composition (\% of total FA) of Pacific cod larvae fed differentially enriched rotifers for 4 wk post-hatch (mean \pm $\mathrm{SEM}, \mathrm{n}=3$ ). ${ }^{\mathrm{a}, \mathrm{b}, \mathrm{c}}$ : different letters represent a significant difference among groups; $\mathrm{p}<0.05, F_{3,7}$ at Week $2, F_{2,5}$ at Week 4,1 -way ANOVA with Tukey's multiple comparison test

\begin{tabular}{|c|c|c|c|c|c|c|c|c|}
\hline \multirow{2}{*}{ Fatty acids } & \multirow{2}{*}{ First feeding } & \multirow[b]{2}{*}{ Diet 1} & \multicolumn{2}{|c|}{ Week 2} & \multirow[b]{2}{*}{ Diet 4} & \multirow[b]{2}{*}{ Diet 2} & \multirow{2}{*}{$\begin{array}{c}\text { - Week } 4 \\
\text { Diet } 3\end{array}$} & \multirow[b]{2}{*}{ Diet 4} \\
\hline & & & Diet 2 & Diet 3 & & & & \\
\hline Total $\left(\mu g \mathrm{mg}^{-1} \mathrm{DW}\right)$ & $86.7 \pm 6.0$ & $58.8 \pm 4.9$ & $75.5 \pm 2.1$ & $65.5 \pm 6.4$ & $54.4 \pm 4.7$ & $86.7 \pm 9.0$ & $61.5 \pm 11.7$ & $50.6 \pm 10.3$ \\
\hline 16:0 & $20.9 \pm 0.3$ & $19.9 \pm 3.0$ & $16.9 \pm 0.7$ & $19.1 \pm 1.8$ & $16.6 \pm 1.0$ & $13.8 \pm 0.5$ & $14.7 \pm 0.6$ & $16.8 \pm 1.2$ \\
\hline $18: 0$ & $4.8 \pm 0.1$ & $7.4 \pm 0.7$ & $6.6 \pm 0.3$ & $7.7 \pm 1.0$ & $6.4 \pm 0.3$ & $5.0 \pm 0.1$ & $5.3 \pm 0.3$ & $6.1 \pm 0.3$ \\
\hline$\sum \mathrm{SFA}^{1}$ & $28.3 \pm 0.3$ & $30.9 \pm 4.7$ & $26.7 \pm 1.0$ & $29.9 \pm 2.8$ & $25.0 \pm 1.5$ & $21.5 \pm 0.5$ & $22.6 \pm 1.0$ & $24.9 \pm 1.6$ \\
\hline $16: 1 \omega-7$ & $2.7 \pm 0.1$ & $2.4 \pm 0.1$ & $4.0 \pm 0.4$ & $3.3 \pm 0.3$ & $2.4 \pm 0.1$ & $4.2 \pm 0.1$ & $3.7 \pm 0.1$ & $2.7 \pm 0.2$ \\
\hline $18: 1 \omega-9$ & $8.5 \pm 0.2$ & $16.6 \pm 1.2$ & $11.9 \pm 1.0$ & $12.3 \pm 0.7$ & $13.6 \pm 0.2$ & $11.7 \pm 0.2$ & $12.9 \pm 0.1$ & $14.6 \pm 1.0$ \\
\hline $18: 1 \omega-7$ & $5.0 \pm 0.1$ & $3.2 \pm 0.1$ & $3.9 \pm 0.1$ & $3.6 \pm 0.3$ & $3.1 \pm 0.1$ & $3.2 \pm 0.0$ & $3.1 \pm 0.1$ & $2.8 \pm 0.2$ \\
\hline$\sum$ MUFA $^{2}$ & $20.2 \pm 0.3$ & $26.3 \pm 1.5$ & $23.8 \pm 1.8$ & $22.9 \pm 1.0$ & $22.2 \pm 0.3$ & $22.6 \pm 0.3$ & $22.7 \pm 0.4$ & $22.7 \pm 1.42$ \\
\hline $18: 2 \omega-6$ & $0.5 \pm 0.0$ & $7.4 \pm 0.8$ & $5.4 \pm 0.6$ & $4.9 \pm 0.5$ & $5.2 \pm 0.3$ & $6.5 \pm 0.2$ & $6.4 \pm 0.2$ & $5.8 \pm 0.3$ \\
\hline $20: 4 \omega-6$ & $2.9 \pm 0.0$ & $3.4 \pm 0.3^{\mathrm{a}}$ & $3.1 \pm 0.2^{\mathrm{a}}$ & $3.2 \pm 0.1^{\mathrm{a}}$ & $4.3 \pm 0.1^{\mathrm{b}}$ & $3.3 \pm 0.0^{\mathrm{a}}$ & $3.8 \pm 0.1^{\mathrm{a}}$ & $4.5 \pm 0.2^{\mathrm{b}}$ \\
\hline $20: 5 \omega-3$ & $15.2 \pm 0.0$ & $9.1 \pm 0.8^{\mathrm{a}}$ & $9.6 \pm 0.3^{a}$ & $7.8 \pm 0.3^{\mathrm{ab}}$ & $5.9 \pm 0.4^{\mathrm{b}}$ & $12.3 \pm 0.2^{\mathrm{a}}$ & $9.9 \pm 0.4^{b}$ & $5.7 \pm 0.1^{\mathrm{c}}$ \\
\hline $22: 5 \omega-6$ & $0.3 \pm 0.0$ & $0.3 \pm 0.0^{\mathrm{a}}$ & $1.4 \pm 0.1^{\mathrm{b}}$ & $2.8 \pm 0.1^{\mathrm{c}}$ & $5.5 \pm 0.2^{\mathrm{d}}$ & $1.7 \pm 0.0^{\mathrm{a}}$ & $3.6 \pm 0.1^{b}$ & $6.5 \pm 0.6^{c}$ \\
\hline $22: 5 \omega-3$ & $1.6 \pm 0.0$ & $5.9 \pm 0.6^{\mathrm{a}}$ & $4.9 \pm 0.1^{\mathrm{ab}}$ & $3.7 \pm 0.2^{\mathrm{bc}}$ & $3.1 \pm 0.1^{\mathrm{c}}$ & $6.2 \pm 0.1^{\mathrm{a}}$ & $4.9 \pm 0.2^{\mathrm{b}}$ & $3.2 \pm 0.1^{\mathrm{c}}$ \\
\hline $22: 6 \omega-3$ & $27.8 \pm 0.1$ & $12.5 \pm 1.0^{\mathrm{a}}$ & $20.2 \pm 2.6^{\mathrm{ab}}$ & $20.4 \pm 1.6^{\mathrm{ab}}$ & $25.1 \pm 0.7^{b}$ & $20.4 \pm 0.3$ & $21.9 \pm 0.5$ & $24.1 \pm 2.3$ \\
\hline$\sum$ PUFA $^{3}$ & $51.3 \pm 0.1$ & $42.8 \pm 3.4$ & $49.5 \pm 2.2$ & $47.2 \pm 2.2$ & $52.8 \pm 1.8$ & $55.7 \pm 0.2$ & $54.7 \pm 0.7$ & $52.4 \pm 3.0$ \\
\hline DHA:EPA & $1.8 \pm 0.0$ & $1.4 \pm 0.1^{\mathrm{a}}$ & $2.1 \pm 0.3^{\mathrm{ab}}$ & $2.6 \pm 0.1^{\mathrm{b}}$ & $4.3 \pm 0.2^{\mathrm{C}}$ & $1.7 \pm 0.1^{\mathrm{a}}$ & $2.2 \pm 0.1^{\mathrm{a}}$ & $4.2 \pm 0.3^{\mathrm{b}}$ \\
\hline
\end{tabular}

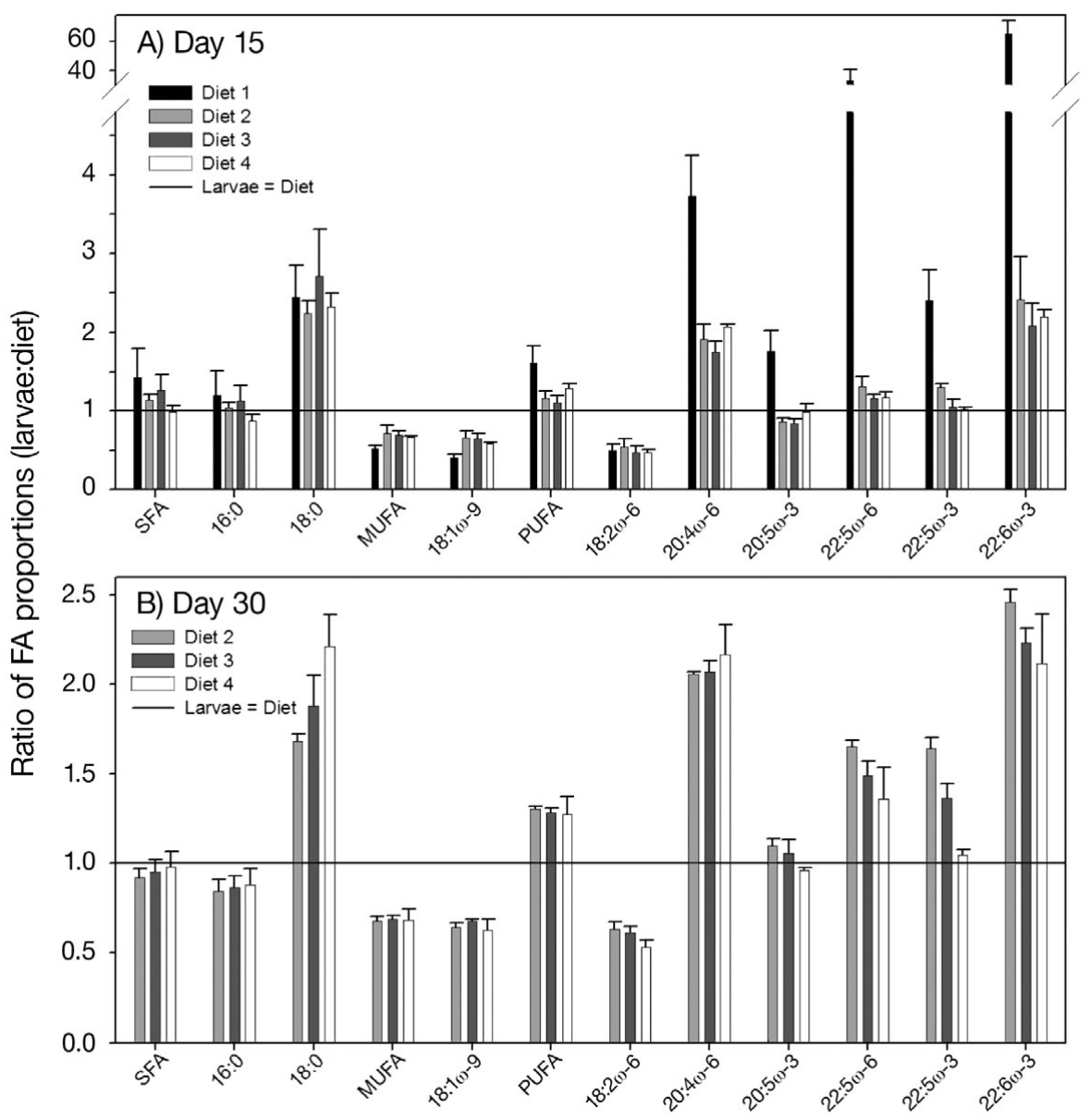

Fig. 3. Gadus macrocephalus. Ratio of specific fatty acids (FA) in larvae compared to dietary levels (larvae:diet) after (A) 2 wk and (B) 4 wk of feeding on 4 differently enriched rotifer diets. Data are mean \pm SEM, $\mathrm{n}=3$. Solid line: proportion of FA in the larvae equals that in the diet $(1: 1)$ 

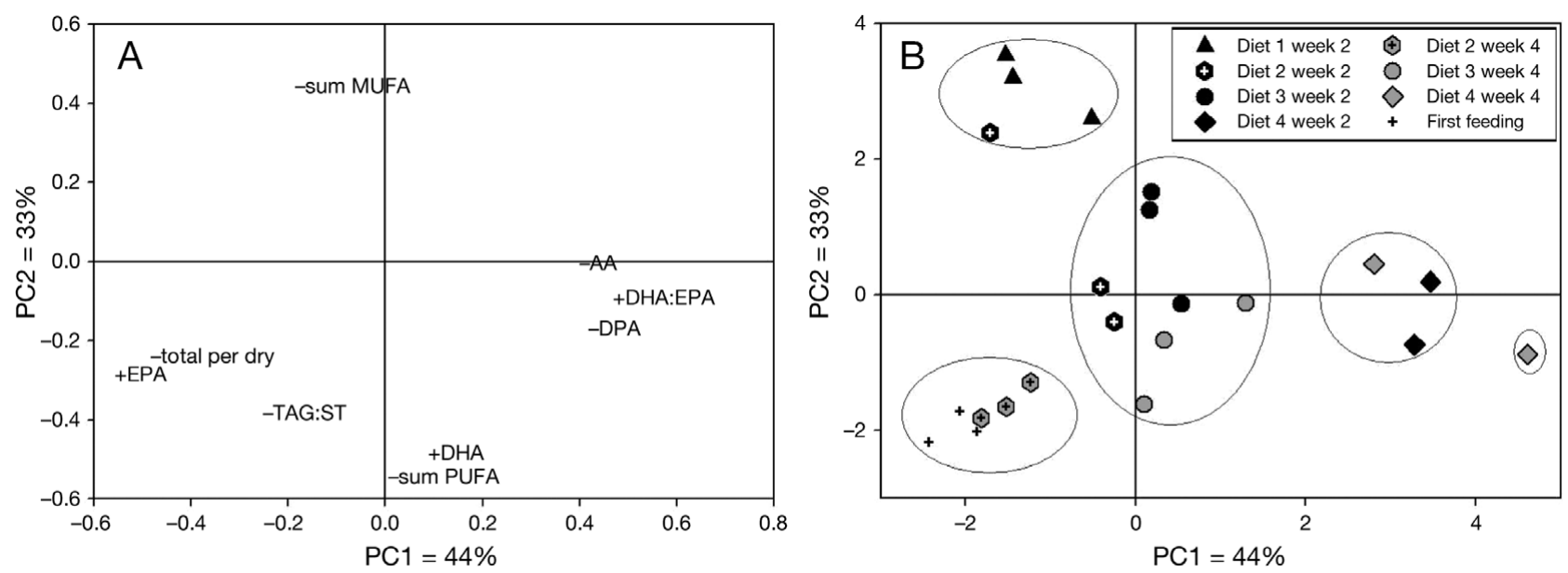

Fig. 4. Gadus macrocephalus. Analysis of the first 2 principal components of lipid data from larvae (first-feeding and feeding for 2 and 4 wk on 4 differentially enriched rotifer diets). The fatty acid and lipid class parameters used were: AA (20:4 $\omega-6)$, DHA $(22: 6 \omega-3), \omega 6 D P A(22: 5 \omega-6)$, EPA $(20: 5 \omega-3)$, DHA:EPA, $\Sigma$ MUFA $=$ monounsaturated fatty acids, total per dry $=$ total fatty acids per dry weight $\mu \mathrm{g} \mathrm{mg}^{-1}$, TAG:ST = triacylglycerols:sterols, $\Sigma$ PUFA = polyunsaturated fatty acids. Groups were determined by cluster analysis of (A) lipid parameter coefficients, symbols represent orientation along the third principal component axis and (B) larval fish scores for the first 2 principal components
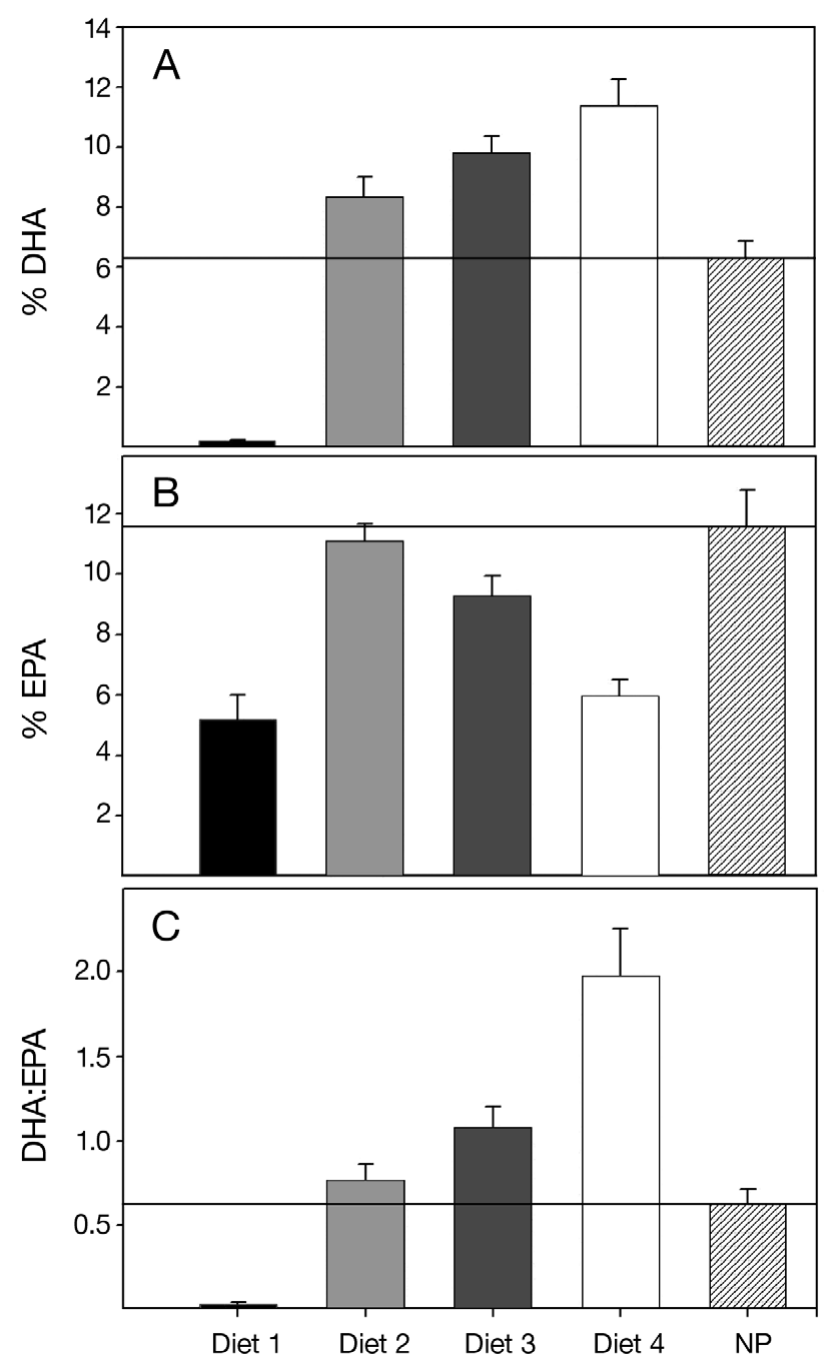

\section{DISCUSSION}

The results of our experiment support our predictions that larval Pacific cod do require high levels of $\omega$-3 PUFA for normal growth and development. Further, energetically similar diets with different DHA: EPA ratios did affect size-at-age and lipid composition. However, Pacific cod larvae did not show a high requirement for DHA relative to EPA but, rather, demonstrated highest growth at ratios ranging from 1.1:1 to 0.8:1. Diets 2 and 3 produced elevated growth and increased lipid condition indices (TAG:ST). After 4 wk of feeding, larvae from Diet 2 most closely resembled the levels of PUFA found in wild-spawned first-feeding Pacific cod larvae (Laurel et al. 2010). Further, the DHA:EPA ratio in Diet 2 rotifers (0.8:1) resembled that reported for 4 species of cold-water Pacific copepods (Neocalanus plumchrus, Calanus marshallae, Euchaeta elongate and Eucalanus bungii, El-Sabaawi et al. 2009b).

The rotifer Brachionus plicatilis is not a natural prey item for Pacific cod. Rotifers, however, are commonly used in both ecological and aquaculture studies on small marine fish larvae (Puvanendran \& Brown 1998,

Fig. 5. Neocalanus plumchrus and rotifers. Relative proportions of (A) docosahexaenoic acid (DHA), (B) eicosapentanoic acid (EPA), and $(\mathrm{C})$ the ratio DHA:EPA in 4 differently enriched rotifer diets and in the calanoid Neocalanus plumchrus (NP; averaged from zooplankton collected over 6 yr in the Strait of Georgia, British Columbia, Canada, see El-Sabaawi et al. 2009a) 
Jordaan \& Brown 2003, Imsland et al. 2006), because they are more easily mass-cultured than wild zooplankton and can be enriched with lipids or FAs to resemble specific prey types. Further, rotifers do not show significant retro-conversion of long chain PUFA into shorter chain PUFA like other live-cultured prey e.g. Artemia (Navarro et al. 1999). Still, fish larvae often grow and survive better on natural prey in the laboratory (e.g. Imsland et al. 2006), likely because lipid-enriched rotifers lack some of the amino acids, vitamins, minerals and digestibility characteristics of wild zooplankton (Sargent et al. 1999, Evjemo et al. 2003). Although Pacific cod larvae would be ideally cultured on marine copepods with variable ratios of EFAs, the techniques for controlled lipid enrichment of marine copepods have not been fully developed (Olivotto et al. 2008). For these reasons rotifers still represent the best vehicle to experimentally examine the effects of prey quality on fish larvae.

Larvae of Pacific and Atlantic cod feed opportunistically on protozoa, copepod nauplii or copepodites in the wild (van der Meeren \& Naess 1993, Takatsu et al. 2002). Takatsu et al. (2002) showed that Pacific cod larvae off Japan consumed a variety of copepod nauplii and copepodites. Over a 3 year study, small larvae (3.6 to $7.0 \mathrm{~mm} \mathrm{TL}$ ) had many nauplii (41 to $83 \%$ of prey items) while large larvae (7.1 to $15.5 \mathrm{~mm}$ TL) had mostly copepodites (80.4 to $99.5 \%$ ) in their guts. Here we examined just the effect of FA composition of 1 livefood on larval size-at-age and condition. Although Pacific cod larvae are capable of growing on rotifers up to 6 wk at similar temperatures (Laurel et al. in press), we cannot rule out the possibility that prey size constrained growth in our larvae during the last week of the experiment. However, this factor would likely have been more significant in larger larvae from Diet 2 \& 3 than for smaller larvae in Diet 1 . Therefore, any potential constraint by prey size in our experiment would have made our conclusions about dietary EFA on sizeat-age somewhat conservative.

We intentionally formulated diets ranging in DHA: EPA ratios to represent the natural annual FA variation in plankton food webs based on diatoms and dinoflagellates (Budge \& Parrish 1998, El-Sabaawi et al. 2009a). Previous studies on lipid nutrition in gadids have largely been based on commercial live-food enrichments, which often vary simultaneously in factors such as total lipids per dry wt, protein, lipid classes as well as multiple FAs (Park et al. 2006, Garcia et al. 2008a). Controlled studies using formulated experimental enrichment oils have been conducted to examine the importance of the essen-

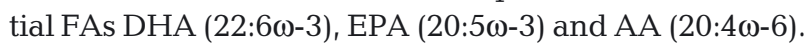
However, most of these studies focus on commercially important Atlantic species (Copeman et al. 2002, Villalta et al. 2005a, Lund et al. 2007).
The functional significance of dietary DHA:EPA can be observed in terms of competitive interactions between FAs for incorporation into PLs; specifically, competition for the enzymes that esterify FAs onto the glycerophospho-based backbone (Sargent et al. 1999). The functional significance of the ratio of DHA:EPA has now been investigated in both primary consumers (Arendt et al. 2005, El-Sabaawi et al. 2009a) and fish larvae (Sargent et al. 1999, Izquierdo et al. 2000) as well as at the ecosystem level (Litzow et al. 2006). Specifically, this ratio has been well studied in relation to the dietary requirements of many marine fish that are candidates for aquaculture. Nutritional requirements for DHA and EPA have been found to be both species- and developmentally-specific (Copeman 2001, Villalta et al. 2005b).

From a population perspective, differences in reproduction and early life history suggest that Pacific cod larvae may be more susceptible to changes in prey quality in the field than Atlantic cod larvae. Although both species are highly fecund, and likely susceptible to high variation in survival during the first few weeks of life (May 1967, McCain 2003), Pacific cod eggs are semi-adhesive and are released in 1 batch during spring (Mecklenburg et al. 2002). This contrasts to Atlantic cod eggs which are pelagic and are released in batch spawning events across several months in spring and fall (Kjesbu 2006). Temporal (i.e. single batch-spawing) and spatial (i.e. reduced dispersal potential of eggs) spawning characteristics have been hypothesized to make Pacific cod more vulnerable to changes in their prey than Atlantic cod (Laurel et al. in press).

Pacific cod also differ from Atlantic cod in their ability to synthesize and convert lipids and FAs during egg development. Pacific cod eggs synthesize large amounts of lipid (presumably from protein) just prior to hatch, and demonstrate extreme conservation and possible synthesis of DHA as yolk-sac larvae (Laurel et al. 2010). This conservation of DHA by Pacific cod may reflect a unique ability to produce DHA from short chain precursors, however, the mechanism for this synthesis needs further investigation. DHA:EPA ratio in wild Atlantic cod eggs has been reported to be 2:1 (Finn et al. 1995) while levels in pre-feeding larvae have been found to be 1.8:1 (Garcia et al. 2008a) or 2.6:1 (Finn et al. 1995). For wild Pacific cod from 2006 and 2008, DHA:EPA ratios are slightly lower in both eggs and newly hatched larvae, 1.5:1 and 1.8:1 respectively (Laurel et al. 2010). Therefore, some of the differences in the natural history of these 2 cod species, coupled with lower levels of DHA:EPA in wild caught samples may indicate a lower dietary requirement for DHA and a higher for EPA in Pacific cod than in their Atlantic congener. 
EPA is an important FA both for inclusion in cell membranes and for the production of biologically active compounds called eicosanoids or 'localized hormones'. AA $(20: 4 \omega-6)$ is also used in the production of these localized hormones that include prostaglandins, thromboxanes, and leukotrienes. In fish, AA is the preferred substrate for the formation of eicosanoids and has been found to produce eicosanoids of higher biological activity than EPA (Bell et al. 1994). Flatfish fed high levels of AA relative to EPA have been found to develop high rates of malpigmentations (Estevez et al. 1999, Copeman et al. 2002). AA is always found in low levels in wild zooplankton and Pacific cod embryos (<2.5\%; Budge \& Parrish 1998, Laurel et al. 2010, ElSabaawi pers. comm.). We offered a range of EPA:AA ratios in our diets with Diet 4 showing the lowest (3:1) and Diet 2 the highest levels (6.9:1). Van der Meeren et al. (2008) measured levels of EPA:AA in a number of copepod species and found them to be never less than 7.5:1 and as high as 49.5:1 due to very low levels of AA in the wild. The importance of this FA has led fish nutritionists to discuss optimum ratios in terms of a three-part index, DHA:EPA:AA, which has been hypothesized to be 10:1:1 (Park et al. 2006) or 11:1.5:1 (Garcia et al. 2008a) in Atlantic cod. Based on our higher weight and lipid condition indices for larvae in Diet 2, we suggest a preliminary dietary ratio of DHA:EPA:AA $=5: 7: 1$ for first-feeding Pacific cod.

Rotifers enriched with all 4 experimental emulsions had the same total lipids per DW and the same proportions of different lipid classes. This ensured that the proximate lipid composition of our rotifers did not differ between dietary treatments. We enriched our rotifers once every $12 \mathrm{~h}$. However, for maximal lipid retention and growth potential these experimental emulsions should ideally be added to rotifer cultures more repeatedly e.g. every $4 \mathrm{~h}$. This is likely why the levels of total lipid per DW in our data were $\sim 11 \%$ while Copeman et al. (2002) reported levels of $\sim 16 \%$ using similar experimental emulsions. Enrichment every $12 \mathrm{~h}$ provided the variation in DHA:EPA ratios that we required to mimic natural variation reported in zooplankton of the North Pacific, despite possible reductions in growth and survival potential.

Temperature and food availability are often emphasized as the most limiting factors regulating the vital rates of fish larvae (Buckley et al. 2004). However, our experiment indicated that prey quality can explain similar variance in growth and survival. Our experiment was conducted at $8^{\circ} \mathrm{C}$, yet Pacific cod larvae exposed to Diet 1 grew at rates similar to Pacific cod larvae reared at $3^{\circ} \mathrm{C}\left(2 \% \mathrm{~d}^{-1}\right.$; Laurel et al. in press $)$. In Diets $2 \& 3$, the observed growth rates (i.e. $\sim 5 \% \mathrm{~d}^{-1}$ ) were on the lower range of those reported for Pacific cod larvae reared at similar temperatures (5 to $12 \%$ $\mathrm{d}^{-1}$ ), but this is likely attributable to using experimental enrichment emulsions as opposed to commercially formulated rotifer enrichments. While Diet 1 was an extreme and unlikely scenario for Pacific cod to face in the field, the growth variation among the 3 PUFA diets was measurable and would likely have significant survival consequences for Pacific cod larvae in the field when faced with size-dependent predation.

Survival at the end of the experiment was low in all treatments, with an average of $6 \%$ in the 3 PUFA diets and only $\sim 1 \%$ in Diet 1 . Mortality of marine fish larvae is extremely high in the field, and in laboratory experiments can be driven by numerous uncontrolled factors and tank effects. Interestingly, survival was much lower after Week 2 than after Week 1, most notably in Diet 1. Further, a reduction in the TAG:ST ratio and proportion of TAG was observed at Week 2. This was followed by a dramatic increase in condition and lipids at Week 4 . Week 2 samples therefore likely contained larvae that had not successfully started feeding or were starving due to inadequate nutrition. Day 13 to 18 post-hatch at $8^{\circ} \mathrm{C}$ is the period at which $100 \%$ mortality occurs in non-feeding Pacific cod larvae (Laurel et al. 2008). Lipid class analysis showed that larvae fed low PUFA had a significantly lower TAG:ST ratio than larvae in all other treatments. Relative improvements in larval condition in other species, such as herring or Atlantic cod, have been attributed to elevated total lipid, TAG per DW, and TAG:ST ratios (Fraser 1989, Lochman et al. 1995).

Although levels of DHA, EPA, and AA have been well investigated for their effects on the early survival, growth, and development in fish and marine invertebrates (Sargent et al. 1999, Arts et al. 2001), more re-

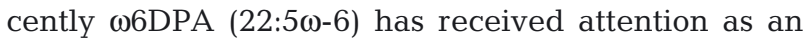
EFA. Parrish et al. (2007) used stable isotope data and FA proportions to show that this FA was conserved at very high levels in larval tissue. Further isotopic evidence showed that these high levels were due to conservation of this long chain $\omega-6$ PUFA rather than increases due to chain elongation of shorter chain precursors. Our results confirm that this FA was also conserved at high levels in Pacific cod larvae, at a rate of $1.5 \times$ what was found in the diet. This is similar to the level of conservation of $13 \mathrm{DPA}$ and lower than the levels of $2.5 \times$ seen for DHA in all larvae at Week 4 . Despite the conservation of this FA in larval tissues, inclusion in the diet of Pacific cod did not result in increased growth or survival. This is contrary to reports for both larval Atlantic cod and larval scallops (Argopecten irradians), where $\omega 6 \mathrm{DPA}$ has been associated with increased growth (Milke et al. 2006, Garcia et al. 2008b). However, the addition of this FA to the diet of larval haddock did not increase growth or survival despite retention of this FA at high levels within larval tissues 
(Garcia et al. 2008b). Future work is required to test the importance of this FA to the growth and survival of marine species without simultaneous variation in other highly essential FAs such as DHA and EPA. It has been suggested that this FA can be used as a C22 PUFA substitute in larval tissues when inadequate levels of DHA are present in the diet (Garcia et al. 2008a).

\section{Conclusions}

In the North Pacific, shifts between EPA-rich diatoms and DHA-rich dinoflagellates result in variable DHA: EPA ratios in zooplankton (El-Sabaawi et al. 2009a) but the effects on Pacific marine fish larvae remain poorly studied. We have shown that Pacific cod larvae are sensitive to changes in the ratios of essential PUFA in their diet and that optimum dietary levels are comparable to those seen (on average) in the wild. Therefore, given the sensitivity of marine fish larvae to the nutritional composition of zooplankton, further efforts should be made to determine not only the effect of changes in zooplankton abundance and species composition (Beaugrand et al. 2003, Batten \& Welch 2004, Mackas et al. 2007) but also the effect of changes in essential parameters of zooplankton nutritional quality for fish larvae. Furthermore, it will be important to determine when such prey quality is most critical in developing fish larvae. Given the sensitivity of zooplankton to phytoplankton species composition and FA proportions (El-Sabaawi et al. 2009a) it is likely that food quality will help explain a portion of variability in year class strength observed in Pacific cod throughout the North Pacific.

Acknowledgements. We thank Tom Hurst and Amanda Colton for help with image analysis measures, Michelle Ottmar, and Scott Haines provided laboratory assistance for larviculture and live-food enrichment. We are most grateful to Jeanette Wells and the technical staff in Christopher Parrish's lab for the chromatography of lipid classes and FAs. Thanks to Moti Harel for providing EFA rotifer emulsions and Tim Tripp for captaining boat charters. Drs. Christopher Parrish, Allan Stoner and Michele Davis, and 3 anonymous reviewers gave useful comments and advice on early versions of this manuscript. Thanks also to the North Pacific Research Board (grant \#605) and the Essential Fish Habitat NOAA Fisheries research grants for funding this study. The manuscript is NPRB contribution 247.

\section{LITERATURE CITED}

Arendt KE, Jonasdottir SH, Hansen PJ, Gartner S (2005) Effects of dietary fatty acids on the reproduction success of the calanoid copepod Temora Longicornis. Mar Biol 146: $513-530$

Arts MT, Ackman RG, Holub BJ (2001) 'Essential fatty acids' in aquatic ecosystems: a crucial link between diet and human health and evolution. Can J Fish Aquat Sci 58:122-137
Batten SD, Welch DW (2004) Changes in oceanic zooplankton populations in the north-east Pacific associated with the possible climatic regime shift of 1998/1999. Deep-Sea Res II 51:863-873

Beaugrand G, Brander KM, Lindley JA, Souissil S, Reid PC (2003) Plankton effect on cod recruitment in the North Sea. Nature 426:661-664

Bell MV, Dick JR (1991) Molecular species composition of the major diacylglycerophospholipids from muscle, liver, retina, and brain of cod (Gadus morhua). Lipids 26: 565-573

> Bell JG, Tocher DR, Sargent JR (1994) Effect of supplementation of 20:3(n-6), 20:4(n-6) and 20:5(n-3) on the production of prostaglandins $\mathrm{E}$ and $\mathrm{F}$ of the 1-, 2- and 3-series in turbot (Scophthalmus maximus) brain astroglial cells in primary culture. Biochim Biophys Acta 1211:335-342

Bell MV, Batty RS, Dick JR, Fretwell K, Navarro JC, Sargent JR (1995) Dietary deficiency of docosahexaenoic acid impairs vision at low light intensities in juvenile herring (Clupea harengus L.). Lipids 30:443-449

Brown JA, Minkoff G, Puvanendran V (2003) Larviculture of Atlantic cod (Gadus morhua): progress, protocols and problems. Aquaculture 227:357-372

Buckley LJ, Caldarone EM, Lough RG (2004) Optimum temperature and food-limited growth of larval Atlantic cod (Gadus morhua) and haddock (Melanogrammus aeglefinus) on Georges Bank. Fish Oceanogr 13:134-140

Budge SM (1999) Fatty acid biomarkers in a cold water marine environment. PhD thesis. Memorial University of Newfoundland, St. John's, Newfoundland

Budge SM, Parrish CC (1998) Lipid biogeochemistry of plankton, settling matter and sediments in Trinity Bay, Newfoundland. II. Fatty acids. Org Geochem 29:1547-1559

Budge SM, Parrish CC, McKenzie CH (2001) Fatty acid composition of phytoplankton, settling particulate matter and sediments at a sheltered bivalve aquaculture site. Mar Chem 76:285-303

Copeman LA (2001) Lipid nutrition during early development of yellowtail flounder (Limanda ferruginea). M.Sc. Thesis, Aquaculture Program, Memorial University of Newfoundland, St. John's, Newfoundland

Copeman LA, Parrish CC (2003) Marine lipids in a cold coastal ecosystem: Gilbert Bay, Labrador. Mar Biol 143: 1213-1227

> Copeman LA, Parrish CC, Brown JA, Harel M (2002) Effects of docosahexaenoic, eicosapentaenoic, and arachidonic acids on the early growth, survival, lipid composition and pigmentation of yellowtail flounder (Limanda ferruginea): a live food enrichment experiment. Aquaculture 210: 285-304

Copeman LA, Parrish CC, Gregory R, Wells J (2008) Decreased lipid storage in juvenile Atlantic cod (Gadus morhua) during settlement in cold-water eelgrass habitat. Mar Biol 154:823-832

> Cushing DH (1990) Plankton production and year-class strength in fish popoulations-an update of the match mismatch hypothesis. Adv Mar Biol 26:249-293

Dhert P, Rombaut G, Suantika G, Sorgeloos P (2001) Advancement of rotifer culture and manipulation techniques in Europe. Aquaculture 200:129-146

> Dunstan GA, Volkman JV, Barrett SM, Leroi J, Jeffrey SW (1994) Essential polyunsaturated fatty acids from 14 species of diatom (Bacillariophyceae). Phytochem 35:155-161

> El-Sabaawi R, Dower JF, Kainz M, Mazumder A (2009a) Interannual variability in fatty acid composition of the copepod Neocalanus plumchrus in the Strait of Georgia, British Columbia. Mar Ecol Prog Ser 382:151-161 
El-Sabaawi R, Dower JF, Kainz M, Mazumder A (2009b) Characterizing dietary variability and trophic positions of coastal calanoid copepods: insight from stable isotopes and fatty acids. Mar Biol 156:225-237

Estevez A, McEvoy LA, Bell JG, Sargent JR (1999) Growth, survival, lipid composition and pigmentation of turbot (Scophthalmus maximus) larvae fed live-prey enriched in arachidonic and eicosapentaenoic acids. Aquaculture 180: 321-343

Evans RP, Parrish CC, Zhu P, Brown JA, Davis PJ (1998) Changes in phospholipase A(2) activity and lipid content during early development of Atlantic halibut (Hippoglossus hippoglossus). Mar Biol 130:369-376

Evjemo JO, Reitan KI, Olsen Y (2003) copepods as live food organisms in the larval rearing of halibut larvae (Hippoglossus hippolglossus L.) with special emphasis on the nutritional value. Aquaculture 227:191-210

Finn RN, Henderson JR, Fyhn HJ (1995) Physiological energetics of developing embryos and yolk-sac larvae of Atlantic cod (Gadus morhua). II. Lipid metabolism and enthalpy balance. Mar Biol 124:371-379

Folch J, Lees M, Sloane SG (1957) A simple method for the isolation and purification of total lipids from animal tissues. J Biol Chem 22:497-509

Fraser AJ (1989) Triacylglycerol content as a condition index for fish, bivalve, and crustacean larvae. Can J Fish Aquat Sci 46:1868-1873

Garcia AS, Parrish CC, Brown JA (2008a) A comparison among differently enriched rotifers (Brachionus plicatilis) and their effect on Atlantic cod (Gadus morhua) larvae early growth, survival and lipid composition. Aqua Nutr 13:14-30

Garcia AS, Parrish CC, Brown JA, Johnson SC, Leadbeater S (2008b) Use of differently enriched rotifers, Brachionus plicatilis, during larviculture of haddock, Melanogrammus aeglefinus: effects on early growth, survival and body lipid composition. Aquacult Nutr 14:431-444

Harel M, Koven W, Lein I, Bar Y and others (2002) Advanced DHA, EPA, and ArA enrichment materials for marine aquaculture using single cell heterotrophs. Aquaculture 213: 347-362

Hicks CR (1982) Fundamental concepts in the design of experiments. Holt, Rinehart and Winston, New York

Hunt GL Jr, Stabeno P, Walters G, Sinclair E, Brodeur R, Napp JM, Bond N (2002) Climate change and control of the sourheastern Bering Sea pelagic ecosystem. Deep-Sea Res II 499:5821-5853

> Imsland AK, Foss A, Koredijk R, Folkvord A, Stefansson S, Jonassen TM (2006) Short- and long-term differences in growth, feed conversion efficiency and deformities in juvenile Atlantic cod (Gadus morhua) startfed on rotifers or zooplankton. Aquacult Res 37:1015-1027

> Izquierdo MS, Socorro J, Arantzamendi L, Hernández-Cruz CM (2000) Recent advances in lipid nutrition in fish larvae. Fish Physiol Biochem 22:97-107

- Jordaan A, Brown JA (2003) The risk of running on empty: the influence of age on starvation and gut fullness in larval Atlantic cod (Gadus morhua). Can J Fish Aquat Sci 60: 1289-1298

Kjesbu OS (2006) The spawning activity of cod, Gadus morhua L. 34(2):195-206

> Laurel BJ, Hurst TP, Copeman LA, Davis MW (2008) The role of temperature on the growth and survival of early and late hatching Pacific cod larvae (Gadus macrocephalus). J Plankton Res 30:1051-1060

Laurel BJ, Copeman LA, Parrish C, Hurst TP (2010) The ecological significance of lipid/fatty acid synthesis in develop- ing eggs and unfed larvae of Pacific cod (Gadus macrocephalus). Mar Biol 157:1713-1724

Laurel BJ, Hurst TP, Ciannelli L (in press) An experimental examination of temperature interactions in the 'matchmismatch' hypothesis for Pacific cod larvae. Can J Fish Aquat Sci

> Litzow MA, Bailey KM, Prahl FG, Heintz R (2006) Climate regime shifts and reorganization of fish communities: the essential fatty acid limitation hypothesis. Mar Ecol Prog Ser 315:1-11

Lochman SE, Maillet GL, Frank KT, Taggart CT (1995) Lipid class composition as a measure of nutritional condition in individual larval Atlantic cod (Gadus morhua). Can J Fish Aquat Sci 52:1294-1306

Logue JA, Howell BR, Bell JG, Cossins AR (2000) Dietary n-3 long-chain polyunsaturated fatty acid deprivation, tissue lipid composition, ex vivo prostaglandin production, and stress tolerance in juvenile Dover sole (Solea solea L.). Lipids 35:745-755

Lund I, Steenfeldt SJ, Hansen BW (2007) Effect of dietary arachidonic acid, eicosapentaenoic acid and docosahexaenoic acid on survival, growth and pigmentation in larvae of common sole (Solea solea L.). Aquaculture 273: $532-544$

Mackas DL, Batten S, Trudel M (2007) Effects on zooplankton of a warmer ocean: Recent evidence from the Northeast Pacific. Prog Oceanogr 75:223-252

May AW (1967) Fecundity of Atlantic cod. J Fish Res Board Can 24:1531-1551

McCain B (2003) Essential fish habitat west coast groundfish draft revised appendix. National Marine Fisheries Service Northwest Fisheries Science Center, Seattle, WA

Mecklenburg CW, Mecklenburg TA, Thorsteinson LK (2002) Fishes of Alaska. American Fisheries Society, Bethesda, MD

Meglen RR (1992) Examining large databases: a chemometric approach using principal component analysis. Mar Chem 39:217-237

Milke LM, Bricel VM, Parrish CC (2006) Comparison of early life history stages of the bay scallop, Argopecten irradians: Effects of microalgal diets on growth and biochemical composition. Aquaculture 260:272-289

Morrison WR, Smith LM (1964) Preparation of fatty acid methyl esters and dimethylacetals from lipids with boron fluoride methanol. J Lipid Res 5:600-608

Munk P (1997) Prey size spectra and prey availability of larval and small juvenile cod. J Fish Biol 51A: 340.351.

> Navarro JC, Henderson RJ, McEvoy LA, Bell MV, Amat F (1999) Lipid conversions during enrichment of Artemia. Aquaculture 174:155-166

Olivotto I, Capriotti F, Buttino I, Avella AM, Vitiello V, Maradonna F, Carnevali O (2008) The use of harpacticoid copepods as live prey for Amphiprion clarkia larviculture: Effects on larval survival and growth. Aquaculture 274: $347-352$

> Park HG, Puvanendran V, Kellett A, Parrish CC, Brown JA (2006) Effect of enriched rotifers on growth, survival, and composition of larval Atlantic cod (Gadus morhua). ICES J Mar Sci 63:285-295

> Parrish CC (1987) Separation of aquatic lipid classes by Chromarod thin-layer chromatography with measurement by Iatroscan flame ionization detection. Can J Fish Aquat Sci 44:722-731

Parrish CC, Abrajano TA, Budge SM, Helleur RJ, Hudson ED, Pulchan K, Ramos C (2000) Lipid and phenolic biomarkers in marine ecosystems: analysis and applications. In: Wangersky, PJ (ed) Marine chemistry. Springer-Verlag, Heidelberg, p 193-223 
Parrish CC, Whiticar M, Puvanendran V (2007) Is $\omega 6$ docosapentaenoic acid an essential fatty acid during early ontogeny in marine fauna? Limn Ocean 52:476-479

Puvanendran v, Brown JA (1998) Effect of light intensity on the foraging and growth of Atlantic cod larvae: interpopulation differences. Mar Ecol Prog Ser 167:207-214.

Rainuzzo JR, Reitan KI, Olsen Y (1997) The significance of lipids at early stages of marine fish: a review. Aquaculture 155:103-115

Rodriguez C, Perez JA, Diaz M, Izquierdo MS, FernandezPalacios H, Lorenzo A (1997) Influence of EPA/DHA ratio in rotifers on gilthead seabream (Sparus aurata) larval development. Aquaculture 150:77-89

Saito H, Kotani Y (2000) Lipids of 4 boreal species of calanoid copepods: origin of monoene fats of marine animals at higher trophic levels in the grazing food chain in the subarctic ocean ecosystem. Mar Chem 71:69-82

Sargent JR (1995) Origins and functions of egg lipids: nutritional implications. In: Bromage NR, Roberts RJ (eds) Broodstock management and egg and larval quality. Blackwell Science, Oxford, p 353-372

Sargent JR, Henderson RJ, Tocher DR (1989) The lipids. In: Halver JE (ed) Fish nutrition. Academic Press

Sargent J, McEvoy L, Estevez A, Bell G, Bell M, Henderson J, Tocher D (1999) Lipid nutrition of marine fish during early development: current status and future directions. Aquaculture 179:217-229

St. John MA, Clemmesen C, Lund, Koster T (2001) Diatom production in the marine environment: implications for larval fish growth and condition. ICES J Mar Sci 58: 1106-1113

Stevens DJ, Deibel D, Parrish CC (2004) Species-specific differences in lipid composition and omnivory in Arctic cope-

Editorial responsibility: Hans Heinrich Janssen, Oldendorf/Luhe, Germany pods collected in deep water during autumn (North Water Polynya). Mar Biol 144:905-915

Suantika G, Dhert P, Nurhudah M, Sorgeloos P (2000) Highdensity production of the rotifer Brachionus plicatilis in a recirculation system: Consideration of water quality, zootechnical and nutritional aspects. Aquacult Eng 21: 201-214

Takatsu T, Nakatani T, Miyamoto T, Kooka K, Takahashi T (2002) Spatial distribution and feeding habits of Pacific cod (Gadus macrocephalus) larvae in Mutsu Bay, Japan. Fish Oceanogr 11:90-101

van der Meeren T, Naess T (1993) How does cod (Gadus morhua) cope with variability in feeding conditions during early larval stages? Mar Biol 116:637-647

van der Meeren T, Mangor-Jensen A, Pickova J (2007) The effect of green water and light intensity on survival, growth and lipid composition in Atlantic cod (Gadus morhua) during intensive larval rearing. Aquaculture 265: 206-217

van der Meeren T, Olsen RE, Hamre K, Fyhn HJ (2008) Biochemical composition of copepods for evaluation of feed quality in production of juvenile marine fish. Aquaculture 274:375-397

Villalta M, Estevez A, Bransden MP (2005a) Arachidonic acid enriched live prey induces albinism in Senegal sole (Solea senegalensis) larvae. Aquaculture 245:193-209

> Villalta M, Estévez A, Bransden MP, Bell JG (2005b) The effect of graded concentrations of dietary DHA on growth, survival and tissue fatty acid profile of Senegal sole (Solea senegalensis) larvae during the Artemia feeding period. Aquaculture 249:353-365

Watanabe T (1993) Importance of docosahexaenoic acid in marine larval fish. J World Aquacult Soc 24:152-161

Submitted:September 30, 2009; Accepted: May 17, 2010

Proofs received from author(s): July 29, 2010 